\title{
Gilles de la Tourette syndrome is not linked to contactin-associated protein receptor 2 antibodies
}

\author{
Kurt-Wolfram Sühs ${ }^{1 *}$, Thomas Skripuletz ${ }^{1}$, Refik Pul ${ }^{1}$, Sascha Alvermann ${ }^{1}$, Philipp Schwenkenbecher ${ }^{1}$, \\ Martin Stangel ${ }^{1 \dagger}$ and Kirsten Müller-Vahl ${ }^{2 \dagger}$
}

\begin{abstract}
Background: In Gilles de la Tourette syndrome (GTS) an immunopathogenic influence of autoantibodies is suspected. In familial GTS a disruption of the contactin-associated protein 2 gene (CNTNAP2), coding for the contactin-associated protein 2 (CASPR2), has been reported. Autoantibodies against CASPR2 are associated with other movement disorders like Morvan's syndrome. In addition, positive oligoclonal bands (OCB) in cerebrospinal fluid (CSF) have been found in more than a third of GTS patients, indicating a pathological intrathecal immunoglobulin synthesis. These findings drove the hypothesis that CASPR2 antibodies are involved in GTS.

Methods: In this cross sectional study, 51 patients with GTS were examined for CASPR2 and other autoantibodies. We used indirect immunofluorescence or enzyme-linked visualization in cell-based assays on tissue sections from cerebellum (rat and monkey), hippocampus (rat), and immunoblots for the detection of specific or any other autoantibodies.

Results: Serum samples from 51 GTS patients, mean age $35.0 \pm 13.1 \mathrm{y}$, were analyzed. In none of the 51 GTS sera CASPR2 antibodies were detectable. Neither had we found any other specific autoantibodies (LGI1, NMDAR, AMPA1, AMPA/2 or GABAB1/B2). An anti-nuclear pattern of immunoreactivity was observed in 7/51 (14 \%) samples. In these patients an immunoblot analysis was used to rule out antibodies directed against well-defined intracellular target antigens. A specific anti-neuronal binding pattern could not be seen in any of the tissue sections.
\end{abstract}

Conclusions: The results negate that CASPR2 antibodies play a role in the pathogenesis of Tourette syndrome and do not support the assumption that anti-neuronal antibodies are involved.

Keywords: Tourette syndrome, Antineuronal antibodies, CASPR2, NMDAR, Tic

\section{Findings} Introduction

Gilles de la Tourette syndrome is a chronic neuropsychiatric disorder with an estimated prevalence rate of about $0.6-1 \%$ [1]. It is thought that pathophysiologically both genetic vulnerability and environmental factors - including immunological changes - are involved. Supporting an immunopathogenic influence, elevated concentrations of Tumor necrosis factor alpha (TNF- $\alpha$ ) and Interleukin 12 (IL-12) have been detected in patients with GTS [2]. In

\footnotetext{
* Correspondence: suehs.kurt-wolfram@mh-hannover.de

${ }^{\dagger}$ Equal contributors

${ }^{1}$ Klinik für Neurologie, Medizinische Hochschule Hannover, Carl-Neuberg

Str. 1, 30625 Hannover, Germany

Full list of author information is available at the end of the article
}

addition, positive oligoclonal bands in the cerebrospinal fluid have been found in $38 \%$ of GTS patients [3]. This strongly suggests a pathological intrathecal immunoglobulin synthesis in GTS, because positive OCBs are found in only $3 \%$ of the general population. However, the role of autoantibodies in GTS remains unclear, since contradictory results have been found [4].

In the last decade, several antibodies targeting neuronal surface proteins (especially ion channels) have been identified to be causative in different neurological disorders including idiopathic limbic encephalitis (LE) and Morvan's syndrome [5]. For example in LE AMPA receptor antibodies (AMPA 1 and AMPA 2), which are directed against the GluA1 and GluA2 subunits of AMPA receptors, can be found. In Morvan's syndrome, characterized by peripheral

\section{Biomed Central}


nerve hyperexcitability, an association with the contactinassociated protein 2 (CASPR2) has been demonstrated [6]. Accordingly, clinical improvement following immunotherapy has been reported [7]. In addition, CASPR2 is a known genetic risk factor of autism and has been suggested to play a role in several other neurodevelopmental disorders including ADHD and OCD [8]. CASPR2, expressed in juxtaparanodal regions of myelinated axons prominently in the brain, is linked to voltage gated potassium channels (VGKC) [9]. It is encoded by the contactin-associated protein 2 gene (CNTNAP2). Most interestingly, a disruption of the CNTNAP2 gene by chromosome insertion has been found in a GTS family in both the affected father and two affected children. The authors speculated that the disruption leads to a disturbed distribution of $\mathrm{K}^{+}$channels causing unwanted movements like tics [10]. So far, only one other family - without GTS - has been described with a disrupted CNTNAP2 gene [11]. This observation led to the conclusion that not the disruption of the CNTNAP2 gene, but a dysfunction of the ion channel by CASPR2 antibodies might be causative in GTS. The aim of this study was to investigate for the first time CASPR2 antibodies in sera of a large group of adult patients with GTS.

\section{Methods}

In this study, we included 51 consecutive adult patients with GTS according to DSM-IV-TR confirmed by one of the authors (KMV). All patients were recruited from the Tourette's outpatient clinic at the Hannover Medical School. Blood samples were collected after approval by the ethics committee of the Hannover Medical School. Patients with autoimmune diseases of the CNS were not eligible to participate. All patients gave their written informed consent before entering the study.

From each patient $7.5 \mathrm{~mL}$ blood were drawn, centrifuged at $3500 \mathrm{rpm}$ for $15 \mathrm{~min}$, and serum fresh frozen at $-80{ }^{\circ} \mathrm{C}$. Within one year serum was tested for antibodies using plasmid transfected HEK293 cells (AutoimmuneEncephalitis-Mosaik1 CA 1439-2, Euroimmun, Lübeck, Germany). The transfected cells ectopically expressed either the CASPR2, the N-methyl-D-aspartic acid receptor (NMDAR), the $\alpha$-amino-3-hydroxy-5-methyl-4-isoxazolepropionic acid receptor (AMPAR), the Leucin-rich glioma inactivated protein (LGI1), or the gamma-aminobutyric acid receptor (GABAB1/B2). Patient serum was diluted 1:10 and incubated with the HEK cells on cover slides. Bound antibodies were labelled with secondary goat antihuman fluorescein-conjugated antibodies (Euroimmun, Lübeck, Germany). Serum from CASPR2 and NMDAR positive patients was used as positive control.

To allow detection of antibodies with an unknown target antigen, biochip mosaics containing hippocampal sections (rat), cerebellum (monkey), and non-transfected
EU90 cells (negative control) were used (IIF: GlutamateReceptor-Mosaic 3, FA Euroimmun, Lübeck, Germany). These were incubated with diluted patient sera for $30 \mathrm{~min}$, washed and labelled using fluorescein isothiocyanate (FITC) anti-human IgG as secondary antibody. Furthermore, diluted patient sera (1:10) were incubated with tissue sections from cerebellum (monkey), washed with secondary anti-human IgG antibodies, and visualization was subsequently performed using 33 '-diaminobenzidine (DAB) (Vector Laboratories, Burlingame, USA).

A commercially available recombinant line assay was used to test for antibodies against intracellular antigens: Glutamate-Decarboxylase (GAD), Zinc-Finger Protein 4 (Zic4), Delta/Notch-like Epidermal Growth Factor-Related Receptor (DNER), Glia-Nuclear (SOX1), Paraneoplastic Antigen 1 (Ma1), Paraneoplastic Antigen 2 (Ma2), Amphiphysin, Collapsin-Response-Mediator Protein 5 (CRMP5/ CV2), Purkinje cell Antigen1 (Yo), Neuronal-Nuclear Antigen1 (HuD), Neuronal-Nuclear Antigen 2 (Ri)(ravo PNS 11 Line Assay, ravo Diagnostika, Freiburg, Germany).

For all experiments, antibody binding was assessed by two independent investigators on an Olympus BX61 microscope. GraphPad Prism version 5.04 was used for statistical evaluation.

\section{Results}

Serum samples from 51 GTS patients between 18 and 64 years (age $35.0 \pm 13.1 \mathrm{y}$, mean $\pm \mathrm{SD}$, male/female ratio 3.4:1) were investigated. Using a cell-based assay with transfected HEK293 cells, in none of the 51 patients antibodies against CASPR2 could be detected (see Fig. 1).

Using other specific cell-based assays, we found no evidence for autoantibodies against NMDAR, AMPA1, AMPA2, LGI1, or GABAB1/2 as well. As a screening test for other unspecific neuronal autoantibodies, all sera were incubated with rat tissue sections from cerebellum and hippocampus as well as with monkey cerebellar tissue sections. Visualization was performed either by immunofluorescence or enzyme-linked using $\mathrm{DAB}$ to control unspecific background staining. A specific (e.g. antineuronal) binding pattern could be found in none of the tissue sections. An anti-nuclear pattern of immunoreactivity was observed in tissue sections in 7/51 (14\%) samples. In these 7 patients, in addition, an immunoblot analysis was performed to investigate antibodies directed against well-defined intracellular target antigens. Yet in none of these patients antibodies against these diagnostically relevant antigens could be detected as summarized in Table 1.

\section{Discussion}

So far, there is a controversial discussion, whether autoantibodies are involved in the pathophysiology of GTS. While several studies support this "antibody hypothesis" $[12,13]$, others do not $[14,15]$. Substantial evidence for 

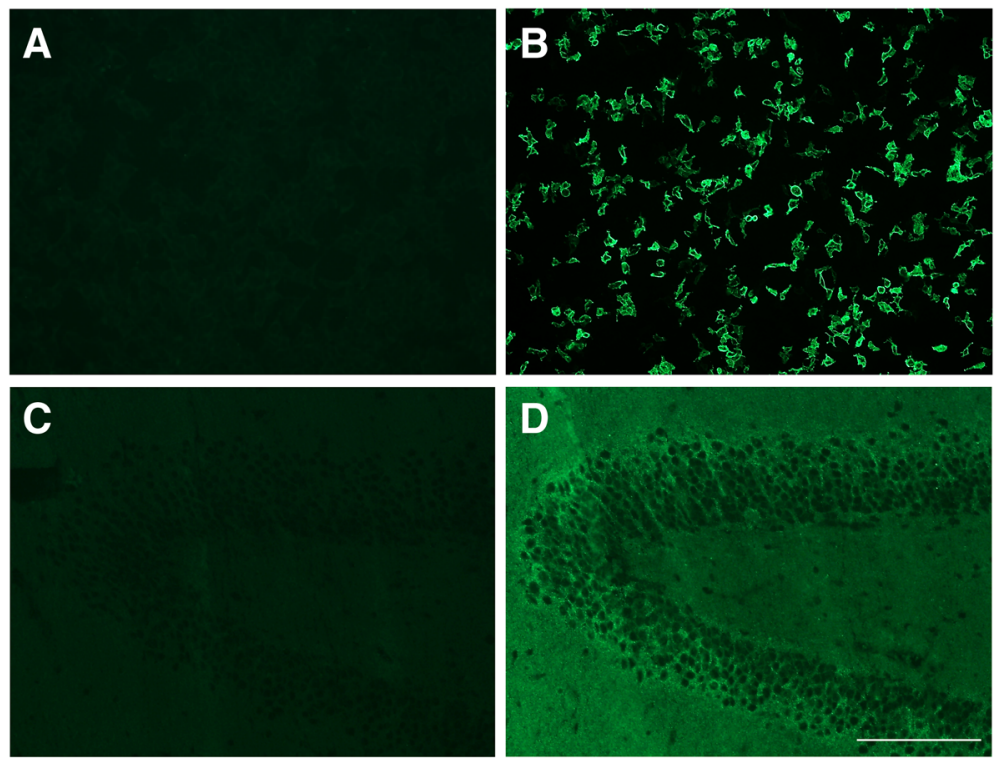

Fig. 1 Transfected HEK cells and hippocampus sections - immunofluorescence. a transfected HEK cells expressing CASPR2, with patients serum depicting no antibody binding, or positive CASPR2 control b, magnification 200fold IIF, scale bar $200 \mu \mathrm{m}$. c Tissue sections of hippocampus (rat) with patient serum and positive CASPR2 control d, magnification 200fold, IIF, scale bar $200 \mu \mathrm{m}$

the antibody-hypothesis comes from findings demonstrating positive CSF OCBs in $38 \%$ of patients indicating intrathecal immunoglobulin synthesis in GTS [3]. In addition, morphological alterations further support this assumption because volume increase of e.g. hippocampus in childhood and volume reduction in adulthood resemble inflammatory processes [16]. So far, several studies have been performed investigating anti-streptococcal antibodies and other specific (aldolase C, neuron-specific enolase, non-neuronal enolase and pyruvate kinase M1) [17] and unspecific anti-neuronal or anti-nuclear antibodies [4]. Despite the different autoantibodies of focus, some of the discrepancies might arise from the techniques used, too. For example, the homogenization of tissue necessary for western blotting, might alter protein structure. On the other hand using tissue sections with IIF a specific intracellular antigen might not be available for antibody binding [4] and different serum dilutions cause variable background staining, at the expense of specificity [14]. Using live differentiated neuronal cells or transfected cell lines most of these methodical drawbacks are mitigated and elevated concentrations of anti-neuronal antibodies have been promoted to separate Sydenham chorea from GTS [18].

In this study, we did not detect CASPR2 antibodies, other well-defined neuronal surface antibodies or unspecific anti-neuronal antibodies in sera of patients with GTS. In tissue sections an anti-nuclear pattern of

Table 1 Method of antibody detection and investigated target antigens

\begin{tabular}{|c|c|c|c|c|c|c|}
\hline \multirow{2}{*}{$\begin{array}{l}\text { Cell based (HEK293) } \\
\text { Surface antigen }\end{array}$} & & & Tissue section & & \multirow[t]{3}{*}{ Immunblot } & \\
\hline & & & \multicolumn{2}{|l|}{ Site (spezies) } & & \\
\hline & Positive & Total & & $\overline{\text { Staining }}$ & & \\
\hline CASPR & 0 & 51 & hippocamcus (rat) & IIF & GAD65 & Amphyphysin \\
\hline Ampa 1 & 0 & 51 & cerebellum (rat) & $\| F$ & Zic4 & CV2 (CRMP5) \\
\hline Ampa 2 & 0 & 51 & cerebellum (monkey) & $\mathrm{DAB}$ & $\operatorname{Tr}(\mathrm{DNER})$ & $\mathrm{Ri}$ \\
\hline LGl 1 & 0 & 51 & & & SOX1 & Yo \\
\hline GABAB $1 / 2$ & 0 & 51 & & & Ma 2 & $\mathrm{HuD}$ \\
\hline \multirow[t]{2}{*}{ NMDAR } & 0 & 51 & & & Ma 1 & \\
\hline & & & $(n=51)$ & & $(n=7)$ & \\
\hline
\end{tabular}

Transfected cells ectopically expressing (CASPR2), N-methyl-D-aspartic acid receptor (NMDAR), a-amino-3-hydroxy-5-methyl-4-isoxazolepropionic acid receptor (AMPAR), Leucin-rich glioma inactivated protein (LGI1), or gamma-aminobutyric acid receptor (GABAB1/B2). Intracellular antigens: Glutamate-Decarboxylase (GAD), Zinc-Finger-Protein4 (Zic4), Delta/Notch-like Epidermal Growth Factor-Related Receptor (DNER), Glia-Nuclear (SOX1), Paraneoplastic Antigen1 (Ma1), Paraneoplastic Antigen2 (Ma2), Amphiphysin, Collapsin-Response Mediator -Protein 5 (CRMP5/CV2), Purkinje cell Antigen1 (Yo), Neuronal-Nuclear Antigen1 (HuD), NeuronalNuclear Antigen2 (Ri) 
immunoreactivity was observed in $7(14 \%)$ of the 51 patients samples, which is in the range of anti-nuclear antibodies in healthy individuals (12-16 \%) [19]. In these patients the immunoblot analysis did not reveal any of the diagnostically relevant anti-neuronal antibodies. Therefore our results do not support the hypothesis that anti-neuronal antibodies in serum are an immunopathogenic factor in GTS. This statement is restricted by the assumption that target antigens presented solely in basal ganglia cells or cortical neurons might have been missed.

To promote an autoantibody as immunopathogenic, localization on target structures, disease induction after passive transfer and remission of symptoms after withdrawal are required conditions [20]. Diametrical results have been found in animal experiments as some groups were able to generate tic like symptoms in rats via antineuronal antibody transfer from GTS patients [21], while others failed to reproduce these results [22]. In order to be able to prove pathogenicity, it is therefore desirable to look for a specific antibody in a disease like GTS.

The appreciable frequency of CASPR 2 antibody seroprevalence is $0.9 \%$ in the general population [23]. Based on a known association of GTS and CNTNAP2 gene disruption which codes for CASPR2 and the role of this antibody in the hyperexcitability in Morvan's disease, we used a cell-based assay to specifically look for antibodies against this protein. The cell-based assay provides the lowest chance of false results since on the one hand epitope structures are unaltered and on the other hand they are presented on the cell surface. However in sera of patients with GTS, we failed to detect CASPR2 antibodies.

A limitation of this study is that we investigated sera, but not CSF to detect autoantibodies in GTS. Some autoantibodies are detected only in the CSF, but not in serum thus, like in many other psychiatric and neurological diseases CSF investigations would be favorable [24]. However, so far, CASPR2 positivity only in the CSF, but not in serum has not yet been described. Particular advantages are: 1) this is a large, prospective, and hypothesis driven study, combining cell-based assays and tissue with different detection methods and 2) frozen serum samples were processed within one year.

In conclusion, neither serum CASPR2 antibodies nor several other serum neuronal surface antigens such as NMDAR play a role in the pathogenesis of GTS.

\footnotetext{
Abbreviations

GTS: Gilles de la Tourette syndrome; CNTNAP2: Contactin-associated protein 2 gene; CASPR2: Contactin-associated protein 2; OCB: Oligoclonal bands; NMDAR: N-methyl-D-aspartic acid receptor; AMPAR: a-amino-3-hydroxy-5methyl-4-isoxazolepropionic acid receptor; AMPA 1 / AMPA 2: AMPA receptor antibodies; LG11: Leucin-rich glioma inactivated protein; GABAB1/B2: Gammaaminobutyric acid receptor; GAD: Glutamate-Decarboxylase; Zic4: Zinc-FingerProtein4; DNER: Delta/Notch-like Epidermal Growth Factor-Related Receptor;
}

SOX1: Glia-Nuclear; Ma1: Paraneoplastic Antigen1; Ma2: Paraneoplastic Antigen2; CRMP5/CV2: Amphiphysin, Collapsin-Response Mediator -Protein 5; Yo: Purkinje cell Antigen1; HuD: Neuronal-Nuclear Antigen1; Ri: Neuronal-Nuclear Antigen2; TNF-a: Tumor necrosis factor alpha; LL-12: Interleukin 12; CSF: Cerebrospinal fluid; ADHD: Attention Deficit Hyperactivity Disorder; OCD: Obsessive-compulsive disorder; VGKC: Voltage gated potassium channels; FITC: Fluorescein isothiocyanate; DAB: 3 3'-diaminobenzidine; IFF: Immunofluorescence.

\section{Competing interests}

The authors declare that they have no competing interests.

\section{Authors' contributions}

KWS contributed to conception of the study, executed it, and wrote the first draft. TS contributed to conception, reviewed and commented the manuscript. RP, SA and PS supported the lab work, reviewed and commented the manuscript. MS contributed to organization of the study, reviewed and commented the manuscript. KMV contributed to conception and organization of the study, reviewed and commented the manuscript. All authors read and approved the final manuscript.

\section{Acknowledgment}

The authors thank Karin Fricke for excellent technical support.

\section{Author details}

${ }^{1}$ Klinik für Neurologie, Medizinische Hochschule Hannover, Carl-Neuberg Str. 1, 30625 Hannover, Germany. ${ }^{2}$ Klinik für Psychiatrie, Sozialpsychiatrie und Psychotherapie, Medizinische Hochschule Hannover, Carl-Neuberg Str. 1, 30625 Hannover, Germany.

Received: 23 July 2015 Accepted: 8 October 2015

Published online: 13 October 2015

\section{References}

1. Kraft JT, Dalsgaard S, Obel C, Thomsen PH, Henriksen TB, Scahill L. Prevalence and clinical correlates of tic disorders in a community sample of school-age children. Eur Child Adolesc Psychiatry. 2012;21:5-13.

2. Leckman JF, Katsovich L, Kawikova I, Lin H, Zhang H, Kronig H, et al. Increased serum levels of interleukin-12 and tumor necrosis factor-alpha in Tourette's syndrome. Biol Psychiatry. 2005;57:667-73.

3. Wenzel C, Wurster U, Muller-Vahl KR. Oligoclonal bands in cerebrospinal fluid in patients with Tourette's syndrome. Mov Disord. 2011;26:343-6.

4. Martino D, Dale RC, Gilbert DL, Giovannoni G, Leckman JF. Immunopathogenic mechanisms in tourette syndrome: a critical review. Mov Disord. 2009;24:1267-79.

5. Gold M, Pul R, Bach JP, Stangel M, Dodel R. Pathogenic and physiological autoantibodies in the central nervous system. Immunol Rev. 2012;248:68-86

6. Irani SR, Alexander S, Waters $P$, Kleopa KA, Pettingill P, Zuliani L, et al. Antibodies to Kv1 potassium channel-complex proteins leucine-rich, glioma inactivated 1 protein and contactin-associated protein-2 in limbic encephalitis, Morvan's syndrome and acquired neuromyotonia. Brain. 2010;133:2734-48

7. Ong E, Viaccoz A, Ducray F, Perol M, Cavillon G, Rogemond V, et al. Dramatic improvement after rituximab in a patient with paraneoplastic treatment-refractory Morvan syndrome associated with anti-CASPR2 antibodies. Eur J Neurol. 2013;20:e96-7.

8. Poot M. Connecting the CNTNAP2 networks with neurodevelopmental disorders. Mol Syndromol. 2015;6:7-22.

9. Poliak S, Gollan L, Martinez R, Custer A, Einheber S, Salzer JL, et al. Caspr 2, a new member of the neurexin superfamily, is localized at the juxtaparanodes of myelinated axons and associates with $\mathrm{K}+$ channels. Neuron. 1999:24:1037-47.

10. Verkerk AJ, Mathews CA, Joosse M, Eussen BH, Heutink P, Oostra BA. CNTNAP2 is disrupted in a family with Gilles de la Tourette syndrome and obsessive compulsive disorder. Genomics. 2003;82:1-9.

11. Belloso JM, Bache I, Guitart M, Caballin MR, Halgren C, Kirchhoff M, et al. Disruption of the CNTNAP2 gene in a t(7;15) translocation family without symptoms of Gilles de la Tourette syndrome. Eur J Hum Genet. 2007;15:711-3. 
12. Rizzo R, Gulisano M, Pavone P, Fogliani F, Robertson MM. Increased antistreptococcal antibody titers and anti-basal ganglia antibodies in patients with Tourette syndrome: controlled cross-sectional study. J Child Neurol. 2006;21:747-53.

13. Martino D, Chiarotti F, Buttiglione M, Cardona F, Creti R, Nardocci N, et al. The relationship between group A streptococcal infections and Tourette syndrome: a study on a large service-based cohort. Dev Med Child Neurol. 2011;53:951-7.

14. Morer A, Lazaro L, Sabater L, Massana J, Castro J, Graus F. Antineuronal antibodies in a group of children with obsessive-compulsive disorder and Tourette syndrome. J Psychiatr Res. 2008;42:64-8.

15. Loiselle CR, Wendlandt JT, Rohde CA, Singer HS. Antistreptococcal, neuronal, and nuclear antibodies in Tourette syndrome. Pediatr Neurol. 2003;28:119-25.

16. Peterson BS, Choi HA, Hao X, Amat JA, Zhu H, Whiteman R, et al. Morphologic features of the amygdala and hippocampus in children and adults with Tourette syndrome. Arch Gen Psychiatry. 2007;64:1281-91.

17. Dale RC, Candler PM, Church AJ, Wait R, Pocock JM, Giovannoni G. Neuronal surface glycolytic enzymes are autoantigen targets in post-streptococcal autoimmune CNS disease. J Neuroimmunol. 2006;172:187-97.

18. Brilot F, Merheb V, Ding A, Murphy T, Dale RC. Antibody binding to neuronal surface in Sydenham chorea, but not in PANDAS or Tourette syndrome. Neurology. 2011;76:1508-13.

19. Satoh M, Chan EK, Ho LA, Rose KM, Parks CG, Cohn RD, et al. Prevalence and sociodemographic correlates of antinuclear antibodies in the United States. Arthritis Rheum. 2012;64:2319-27.

20. Archelos JJ, Hartung HP. Pathogenetic role of autoantibodies in neurological diseases. Trends Neurosci. 2000;23:317-27.

21. Hallett JJ, Harling-Berg CJ, Knopf PM, Stopa EG, Kiessling LS. Anti-striatal antibodies in Tourette syndrome cause neuronal dysfunction. J Neuroimmunol. 2000;111:195-202.

22. Loiselle CR, Lee $\mathrm{O}$, Moran TH, Singer HS. Striatal microinfusion of Tourette syndrome and PANDAS sera: failure to induce behavioral changes. Mov Disord. 2004;19:390-6.

23. Dahm L, Ott C, Steiner J, Stepniak B, Teegen B, Saschenbrecker S, et al. Seroprevalence of autoantibodies against brain antigens in health and disease. Ann Neurol. 2014;76:82-94.

24. Gresa-Arribas N, Titulaer MJ, Torrents A, Aguilar E, McCracken L, Leypoldt F, et al. Antibody titres at diagnosis and during follow-up of anti-NMDA receptor encephalitis: a retrospective study. Lancet Neurol. 2014;13:167-77.

\section{Submit your next manuscript to BioMed Central and take full advantage of:}

- Convenient online submission

- Thorough peer review

- No space constraints or color figure charges

- Immediate publication on acceptance

- Inclusion in PubMed, CAS, Scopus and Google Scholar

- Research which is freely available for redistribution 